IN PRESS

Research in Occupational Stress and Well being (vol. 3). P. Perrewe and D. Ganster (Eds.)

\title{
DISPLAY RULES AND STRAIN IN SERVICE JOBS: WHAT'S FAIRNESS GOT TO DO WITH IT?
}

\author{
Alicia A. Grandey ${ }^{1}$ \\ Pennsylvania State University \\ Glenda M. Fisk \\ Pennsylvania State University
}

\begin{abstract}
The link between emotion display rules and job strain has been well established. This chapter draws upon the organizational justice literature to propose a new individual difference, service emotion rule fairness (SERF), to predict job strain for service workers. We propose that when service workers believe that organizational control of emotional displays is unfair they have poor fit with the job and increased strain. In fact, in the survey and experimental studies presented here, SERF uniquely predicted turnover intentions and emotional exhaustion beyond individual and group characteristics. SERF was rated higher when displays to customers are perceived as a means to gain financial rewards or form relationships with others, supporting a self-interest model of fairness, whereas the extent that display rules made one feel controlled, SERF was lower. We also found evidence that those with more social and organizational power perceived that the requirements were fairer. Practical and research implications are discussed.
\end{abstract}

In 2000, service occupations made up $18 \%$ of the U.S. economy, more than any other non-professional occupation, and employment in the service sector is projected to increase by 5,000 new jobs in 2010 (www.bls.gov, 2003). As more U.S. workers become service employees, the unique characteristics of this work need to be directly examined in the organizational and psychology research (Offermann \& Gowing, 1990). Two unique characteristics of service work are the continual interaction with the public and the requirement to display certain expressions as part of the job (Hochschild, 1983). Service employees work the front lines and act as boundary-spanners - they link the company and the public it serves. In order to manage the public's impressions effectively, service workers are expected to maintain positive expressions, regardless of true feelings. In support of this requirement, the display of positive emotions to customers has been linked with service ratings, customer satisfaction and intentions to return ( Pugh, 2001; Tsai, 2001; Tsai \& Huang, 2002). In fact, positive displays are often enforced by secret shoppers, supervisors, or customer comment cards, and are an explicit part of employee training programs (Hochschild, 1983; Rafaeli \& Sutton, 1987; VanMaanen \& Kunda, 1989). Customers enforce these displays as well because they are aware of such expectations, due to marketing "service with a smile". Thus, service employees as well asothers are likely to

\footnotetext{
${ }^{1}$ The authors would like to thank Patricia Barger, Gary Bolling, Matthew Burgard, Erica Chando, Deanna Danski, Jessica Dzieweczynski, Justin Gottlieb, Stephanie Rodrigues, Kathleen Royer, Rima Rynes and Celia Sucheski for their help with data collection and entry.
} 
agree that service workers are expected to follow emotional "display rules" as part of the job (Ekman \& Friesen, 1975; Rafaeli \& Sutton, 1987).

Despite the organizational benefits associated with smiling at customers, Hochschild (1983) suggested that treating emotional expression as a commodity, a part of the product for monetary exchange, was inherently unpleasant and dehumanizing to the employee. She argued that unlike social exchanges in private life, those in the service encounter are "ritually sealed and almost inescapable" and the exchange has an inherent inequality between the actors (Hochschild, 1983, p. 19). In support of this view, research has demonstrated that employees who are explicitly aware of display rules have lower job satisfaction and higher burnout and health problems than those who do not perceive such rules (Best, Downey, \& Jones, 1997; Schaubroeck \& Jones, 2000).

Of course, individual differences are likely to moderate the relationship between jobrelated display rules and the stress that is experienced as a result of those rules (Arvey, Renz, \& Watson, 1998; Morris \& Feldman, 1996). The affective personality of the employee is one type of individual differences that has been examined (Abraham, 1999; Bulan, Erickson, \& Wharton, 1997; Diefendorff, Croyle, \& Gosserand, in press; Diefendorff \& Richard, 2003; Morris \& Feldman, 1997). In this chapter, we propose a more cognitive type of individual difference: employees' beliefs about the fairness of organizational display rules. That is, to what extent do people believe that it is fair to require that employees smile at customers (no matter what)? What role does perceived fairness of this expectation play in determining job strain? Who is more or less likely to feel this way, and can such attitudes be modified?

In the current chapter, we begin by discussing the links between these emotional requirements and stress. Research on emotion requirements is merged with the organizational justice literature to propose an individual difference for the perceived fairness of display rules, why it should predict job strain, and what the antecedents are. We then provide evidence for this individual difference with a survey study and a laboratory experiment.

\section{Emotion Requirements and Work Stress}

The stressful nature of service work has been well documented (Brotheridge \& Grandey, 2002; Maslach, 1978; Maslach \& Jackson, 1984; Maslach \& Pines, 1977; Singh, Goolsby, \& Rhoades, 1994). Front-line service workers often receive low pay and occupy relatively low status positions in the organizational structure. Moreover, these employees typically possess low levels of job autonomy and high demands in terms of the number of customers they are expected to interact with (Grandey \& Brauburger, 2002; Hochschild, 1979; Wharton, 1993). Thus, service jobs fit into the "high stress" job category in the "demand-control" model of job strain (Karasek, 1979) as discussed by others (Brotheridge \& Grandey, 2002; Pugliesi, 1999).

In addition to these occupational factors, employees who interact with customers or clients are also expected to maintain certain "display rules," or emotional requirements. Though providing service with a smile may seem reasonable, evidence has emerged demonstrating that complying with display rules requires considerable energy and attention. Experimental research has shown that requirements to suppress negative emotions such as disgust or sadness increased physiological arousal compared to people who were permitted to express their true emotions (Gross \& Levenson, 1993, 1997). Furthermore, requirements to "hide negative" and "show positive" have been associated with increased levels of burnout in field studies (Schaubroeck \& Jones, 1998) and in work simulations (Sideman \& Grandey, 2003).

Though display requirements themselves may decrease feelings of autonomy and be inherently stressful, more arousal and strain is expected if the display rules are discrepant from employees' emotional state (Hochschild, 1983). In other words, creating "a physical or publicly observable facial and bodily display" (Hochschild, 1983, p. 7) is psychologically taxing when required behavior conflicts with the authentic self (e.g., Ashforth \& Humphrey, 1993; Ashforth \& Tomiuk, 2000; Hochschild, 1983; Morris \& Feldman, 1996). Since most service work display requirements 
involve hiding negative emotions and/or showing positive emotions, experiencing negative emotions at work would create a discrepancy between the current state and the standard (Diefendorff \& Gosserand, 2003). Previous theorists and researchers have proposed the contextual and dispositional factors that may make such a discrepancy more likely and therefore, make display rules more stressful. These factors include (a) situational factors and (b) a negative or inexpressive personality style. To these two factors we add a third explanation (c) perceived fairness of display rule policies. We briefly describe the first two below, then focus on the third.

\section{Situational Factors}

Two factors than increase the stress of service work are negative events and low job autonomy (Grandey \& Brauburger, 2002). Negative events create a discrepancy between display rules and emotions, and thus stress during service work. One type of negative event is the extent that the public is rude or aggressive toward service employees (Grandey, Dickter \& Sin, 2004; Maslach, 1978). In a sample of care workers, frequent interactions with clients led to burnout due, in part, to "hostility directed at the staff person" (Maslach, 1978, p. 112). In a diary study of student workers (Grandey, Tam \& Brauburger, 2002), higher levels of interpersonal conflict (yelling, rudeness) were reported coming from customers as compared to coworkers and supervisors. The power differential between the customer (who is 'always right') and the service employee may increase the likelihood that stress occurs (Allan \& Gilbert, 2002). Aggression or conflict from customers has been associated with service worker burnout (Grandey et al., 2004).

The extent of job autonomy is another situational factor that has also been proposed to influence the strain of service workers (Grandey \& Brauburger, 2002; Spector, 1986). In a study of U.S. and French employees who had contact with the public, Grandey and colleagues found that workers with high levels of job autonomy were less burned out as a result of regulating expressions than were those with low autonomy (Grandey, Fisk, \& Steiner, 2004). A sense of control makes work demands less stressful (Karasek, 1979).

\section{Dispositional Factors}

Morris and Feldman (1997) proposed that "the greater the conflict between felt and sanctioned expressed emotion the more emotional exhaustion is experienced" (p.267). Certain dispositional factors may make following display rules more or less demanding (Ashforth \& Humphrey, 1993; Morris \& Feldman, 1996). Pugh (2001) found that employees who are more emotionally expressive were more likely to smile and make eye contact with customers. Negative affectivity has also been linked to both effortful regulation and burnout (Brotheridge \& Grandey, 2002). New research has begun to explore general personality traits as factors predicting the strain of emotional labor (Diefendorff, et al., in press; Tews \& Glomb, 2003). This stream of research suggests that people experience strain in service jobs when they lack the predisposition toward, or ability to naturally show, expressions that are congruent with display rules.

\section{Fairness Beliefs about Service Employee Emotion Display Rules}

Another explanation for the strain of service worker, beyond the situational factors and the ability to express required emotions, is the willingness or motivation to comply with interpersonal demands. Given the stressful nature of service work, as well as the fact that such jobs are typically characterized by low pay and low status, it is understandable that employees may perceive display rules as an unfair expectation inducing a sense of conflict and strain. Hochschild (1983) suggested that making emotions into a sold commodity is itself untenable. Customers treat an employee's expressions as their personal property, such as the customer who asks the hotel clerk "What, no smile this morning?" (Terkel, 1972, p. 247), and such external controls of expression may seem unfair. These controls are often quite explicit: in one grocery store management insisted that employees smile, provide a greeting and 3seconds of eye contact with customers and undercover shoppers enforced the policy. Said one clerk: "I really don't think it should be required. I'm going to treat people nice regardless. I don't like it that they watch you 
and listen to you and that you could get fired" (Cabanatuan, 1998). A recent legal case brought to light suggests that display rules may be interpreted and reciprocated by some customers in an inappropriate manner (e.g., flirting), leading to sexual harassment claims from employees (Curtis, 1998). Thus there the negative events and lack of autonomy that may inspire stress may also inspire a sense of injustice regarding the requirement to be friendly to employees, and this fairness perception may be the more proximal predictor of job strain. We explore this possibility and propose the construct Service Emotion Rules Fairness, or SERF.

Service Emotion Rules Fairness (SERF) and Job Strain

Fairness of organizational policies have been linked to negative work outcomes (Colquitt, Conlon, Wesson, Porter \& Ng, 2001). For example, those who believe that policies are unfair (procedural injustice) are more likely to be dissatisfied with their jobs (Mossholder, Bennett, Kemery, \& Wesolowski, 1998) and withdraw from work (Masterson, Lewis, Goldman, \& Taylor, 2000). Research also suggests that injustice resulting from one's work role is stressful (Colquitt et al., 2001; Zohar, 1995) and that perceptions of unfairness can evoke stress emotions such as anger (Mikula, Scherer, \& Athenstaedt, 1998; Weiss, Suckow, \& Cropanzano, 1999).

Since previous research has demonstrated links between justice perceptions and well-being or strain, we propose that to the extent display requirements are perceived as unjust more job strain will be experienced by those working under such requirements. Believing that emotional display rules are generally unfair for service workers represents a set of beliefs or values about emotional control (Martin, Knopoff \& Beckman 1998). When core beliefs are incongruent with required behaviors of the job, role conflict ensues. In fact, it may even be that compromising "core values regarding appropriateness of emotional displays represents such a fundamental attack on the self that the alienation and hostility aroused are more severe than other forms of role conflict" (Abraham, 1999, p. 451). Thus, if people find display rules to be an unfair job requirement for service workers, this should help explain stress outcomes for those who work in these positions.
As discussed above, Hochschild (1983) argued that display rules were stressful because they removed personal autonomy and identity as well as induced emotional dissonance, a state of tension. The perception that these requirements are fair may aid in strengthening our understanding of these relationships. To the extent that display rules are viewed as unfair expectations, job strain will be enhanced. This fairness perception bespeaks the extent of role conflict between one's authentic and organizational self. Those who believe that modifying expressions for the public is appropriate for service workers will be more willing to follow such demands, while those who find this to be an unfair "extra" demand will be more resistant and in turn, report job strain. Importantly, we expect these factors to exist when controlling for situational factors and affective personality.

Proposition 1. SERF will negatively relate to the extent of job strain for those with customer contact.

\section{Formation of Fairness Perceptions: Process- Content Distinction}

To provide validity evidence for SERF and to understand the antecedents of this perception, we draw on the process-content distinction of justice. This speaks to how outcomes are decided (process approach) and the factors associated with such outcomes (content approach) (Greenberg, 1987). This taxonomy may be used to understand the notion of justice as a "class of motivated behavior" in that individual and contextual circumstances can create a sense of injustice which in turn, may prompt cognitive and emotional reactions (Cropanzano, Byrne, Bobocel, \& Rupp, 2001, p.166).

Process: Fairness of the Policy. A process approach helps explain why explicit display rules (enforced via selection, training and rewards) may be viewed as an unfair policy. In short, display rules create a loss of voice and personal control. First, display rules stand in stark contrast to the "fair process" or "voice" criteria (Leventhal, 1976). Display rules regard emotional feelings and expressions as separable (Ashforth \& Humphrey, 1993; Morris \& Feldman, 1996); thus, display rules may be 
viewed as a loss of voice in terms of one's emotional self-expression. There is also little opportunity for the low status service employee to request exceptions, alterations, or amnesty from display rules, as illustrated by the grocery store case illustrated earlier. Second, the degree of personal control over behavior is a key factor influencing how individuals respond to both the "fairness and desirability of procedures" (Tyler, 1994, p. 851). Thus, display rules create a social dilemma as they require individuals to devote resources to the organization while simultaneously putting them at "risk of exploitation, rejection and a loss of identity" (Cropanzano, et al., 2001, p.169). The extent that display rules are perceived as taking control away from the individual should influence the extent that the policies are viewed as unfair.

Proposition 2: Perceiving that display rules reduce personal control will be negatively related to SERF.

Content: Fairness of the Outcomes of the Policy. Content approaches to justice suggest that the appraisal of outcomes, whether those outcomes are instrumental or relational, contribute to perceptions of fairness (Cropanzano \& Ambrose, 2001; Cropanzano et al., 2001; Lind \& Tyler, 1988). From an instrumental perspective, display rules should be perceived as fair as long as they ultimately act in the selfinterest of the employee (Cropanzano \& Ambrose, 2001). One obvious type of outcome is one's wage or tips. Restaurant servers who follow positive display rules gain larger tips (Tidd \& Lockard, 1978). However, many employees with display rules are not well-compensated for this type of work - service/front-line jobs are among the lowest paid jobs (Glomb, KammeyerMueller, \& Rotundo, in press). Thus, service employees may find display rules unfair in that they potentially create distributive inequities. Compared with the lower effort that may seem to be required by employees in different, yet higher paying jobs (e.g., sales, clerical workers, computer maintenance), service employees may feel distributive injustice in the sense that they must not only perform in a technically proficient manner, but also make the effort to smile at customers. In contrast, if employees believe that they are being compensated for their emotional displays, display rules are likely to be viewed as more fair.

Proposition 3: Instrumental outcomes will have a positive relationship with perceived fairness of display rules.

The relational approach to fairness suggests that procedures reflect the status of one's social position and more specifically, provide individuals with a "positive sense of identity and feelings of self-worth and selfrespect" (Tyler, 1994; p. 858). From this vantage point, display rules may be perceived as unfair in that front-line employees are subject to rules while individuals higher in the organization may not be (i.e., the rules lack consistency or neutrality) (Cropanzano \& Ambrose, 2001). Moreover, display rules are implemented with little concern for employee interests, thereby reinforcing service workers low status (e.g., Cropanzano \& Ambrose, 2001; Lind, 1995). Thus, whether or not display rules are viewed as fair depends on the extent to which service workers feel such rules either undermine or strengthen their relational outcomes. For example, Tolich (1993) discussed that cashiers were friendly to customers because they gained enjoyment from the interactions. While both instrumental and relational models inform fairness, Tyler (1994) notes that relational models drive justice perceptions. Indeed, the earliest conceptualizations of justice underscore the social nature of fairness. Thus, we expect that when display rules are viewed as providing positive relational outcomes, they will more strongly predict fairness than when they contribute to instrumental rewards.

Proposition 4. Perceived relational outcomes will have a positive relationship with perceived fairness of display rules, beyond instrumental outcomes.

Group Differences in the Perceived Fairness of Display Rules

Attitudes toward external controls on emotional expression may not only vary by individual, but also by group membership. Social groups may vary in their norms regarding emotional displays, and thus may vary in their 
sense of what is "right" about emotional control. Thus, there may be differences in the perceived fairness of display rules in service encounters by gender, race, and job status. Differences in some or all of these factors mean some groups are more at risk for strain when performing emotional labor.

\section{Gender}

Women are socialized to handle the challenges of working with and caring for others emotionally and to 'be nice' when interacting with others (Wharton, 1993; Wharton \& Erickson, 1995). Women tend to be more likely to hold a job where smiling at others is a prerequisite (Hochschild, 1983). Females view being inexpressive in a situation that has display rules to be censurable and that expressing negative emotions is incompatible with being feminine (Haynes, Levine, Scotch, Feinleib, \& Kannel, 1978; Lerner, 1985). In fact, women are seen as more likable when expressing positive emotions than men are (Fischer, 1993; Shields, 1987). On the other hand, males are more likely to expect negative outcomes for being expressive (Graham, Gentry, \& Green, 1981), and are more likely to engage in expressions as a social signal than for their value in securing relational or instrumental outcomes (Bugental, Love, \& Gianetto, 1971). Thus, we expect that women are more likely to view positive displays to customers as leading to instrumental and relational rewards than men, and are therefore more likely to view display rules as fair.

Proposition 5a: Women will be more likely to believe in instrumentality and relational outcomes from following display rules with the public than men.

Proposition 5b: Women will have higher SERF ratings than men.

\section{Race/Ethnicity}

In addition to gender considerations, minority group members may be less likely than majority group members to feel that display rules reflect an equitable work-related demand. We expect that minority members would be more likely to view the policy as unfair because it is seen as removing a personal resource (i.e., emotional control and self-expression) from a group with limited resources and because the display expectations are more difficult to meet for those who are not in the majority group (Clark, Anderson, Clark, \& Williams, 1999). Minorities typically have lower social status than the majority members of society and still face negative stereotypes (Clark et al., 1999). Thus, ethnic minorities must control their emotions day-to-day in an effort to handle impression formation with the higher-status majority members (Rosenfeld, Giacalone, \& Riordan, 1994). In fact, Latinos, Asian American and African American participants were more likely to report suppressing emotions than Caucasians (Gross \& John, 2003). Ethnic minorities are more likely to deal with negative interpersonal events (e.g., racism) that make adherence to display rules difficult and stressinducing (Clark et al., 1999). In one study of service workers and race, Hispanic call center workers reported more verbally hostile customers than other employees (Grandey, et al., 2004). Such hostile conditions may lead minority employees to feel as though display rules are less fair than majority members. In fact, in an examination of U.S. racial groups, Matsumoto (1993) noted that Caucasian participants rated emotional display rules as being more appropriate in a variety of settings (e.g., in public, with acquaintances) than members of minority groups (e.g., African, Asian and Hispanic Americans).

Proposition 6a: Minority employees will be more likely to perceive that display rules are controlling than Caucasians.

Proposition 6b: Minority employees will report lower SERF ratings than Caucasians.

\section{Job Status/Power}

In general, service work is routine and scripted, with very little autonomy or decision latitude given to the employee. A social situation where employee behavior (such as emotional expression) is determined by external sources reflects a lack of power and autonomy (Brotheridge \& Grandey, 2002; Emerson, 1962). In any social setting, the person of higher power typically has more freedom to express true feelings than the lower-power individual (Hecht \& LaFrance, 1998; Henley, 1977; LaFrance \& Hecht, 1999). Managers and professionals 
typically have more autonomy or choice about when positive displays should be shown than service personnel (Leidner, 1996). As Goffman (1967) observed, "the superordinate has the right to exercise certain familiarities which the subordinate is not allowed to reciprocate" (p. 64). These claims are corroborated by work showing that although positive affect is positively associated with smiling for high power persons, this relationship does not hold for low power persons (Hecht \& LaFrance, 1998). Those who hold higher status jobs should be more likely to view display rules as fair because they still have more latitude in how they follow these rules. Furthermore, those in higher status jobs may believe it is fair for those in lower status positions to control their emotions toward them, as fits social norms for emotional expression.

Proposition 8: People in higher power positions will have higher SERF than employees in lower power positions.

The following sections describe two studies that provide evidence for these initial propositions. Study 1 provides psychometric evidence for a scale of SERF and tests it as a correlate of turnover intentions, one sign of job strain. Study 2 tests SERF as a predictor of subsequent strain after doing service work under display rules.

\section{STUDY 1: CONSTRUCT VALIDITY STUDY}

\section{Methods}

\section{Participants and Procedures}

Six members of a research group recruited participants from different areas of the Eastern U.S. and Canada. In total, one hundred and sixteen individuals were surveyed regarding the affective demands of their work. The criteria for identifying participants was that they needed to be working over 16 hours a week ( 2 full work days), be non-students, and interact with the public as part of the job. One hundred and four of the respondents met these criteria.

The respondents were mostly (66\%) female who were employed full-time $(70 \%)$ in various organizations. On average, they had worked at their position for about 8 years and were about 40 years old (range $=19$ to 72 years).
Participants held jobs in service (16\%), caring $(15 \%)$, sales (15\%), manager/professionals $(22 \%)$, clerical or administrative $(17 \%)$ and technical/physical (19\%). Note again that all interacted with customers. On average, respondents worked 38 hours per week and interacted with 12 customers per hour.

\section{Measures}

SERF. Seven items were developed to tap the fairness of display rules for service work (see Table 1 for items). Participants were asked "To what extent do you agree with the following statements about service work (not necessarily your job, but service work in general)?” and given a 1 (strongly disagree) to 5 (strongly agree) Likert-type scale. Sample items include: "It seems unfair for service employees to have to smile at customers in addition to everything else" (reversed) and "Smiling at customers even when you are upset seems like a fair request to make of employees." Two items were reversecoded to minimize the effect of a response bias. Details about psychometric qualities are reported in Table 1.

\section{INSERT TABLE 1 ABOUT HERE}

Perceptions of policy and outcomes. Nine items from Adelmann (1995) followed the stem "to what extent do you agree or disagree that being friendly and smiling at customers during the workday have the following outcomes for you, generally speaking". These items referred to a variety of outcomes (see Table 1) associated with positive displays, including financial, interpersonal, selfexpression, and loss of control.

Affective Personality. The PANAS (Watson, Clark, \& Tellegen, 1988) was used with trait instructions. Subjects were asked "To what extent do you generally feel this way, on average, across all situations?" for twenty affective terms (e.g., hostile, excited), and rated each positive and negative term on a scale of one (very slightly or not at all) to five (extremely). Positive affectivity exhibited an alpha of .83 and negative affectivity's internal consistency was .85. A self-rated measure of expressive ability (i.e., expressive confidence) developed by emotions researchers (Gross \& John, 1998) was 
also included. This scale is primarily comprised of self-monitoring items from the 'performing for others' dimension, and taps one's sense that they are comfortable and able to put on a show or act for others in any situation. Thirteen items were used in the current study (alpha $=.87$ ).

Job Strain. Withdrawal is often a behavioral sign of strain or dissatisfaction, and is a critical outcome to understand in high turnover service occupations. Intent to leave the organization was tapped with three items developed by Cropanzano and colleagues (Cropanzano, James, \& Konovsky, 1993) and had an alpha coefficient of .83.

Group membership. Participants were asked to report their gender, their ethnic identity, and their job title (which was converted into six job categories as done previously by Brotheridge and Grandey, 2002).

\section{Results \& Discussion}

\section{SERF and Perceptions of Outcomes}

To ensure that the perceptions of fairness of display rules was distinct from the perception of outcomes from those display rules, an exploratory principal component analysis with varimax rotation was performed with the seven SERF items and the nine outcomes items. Four components with eigenvalues over 1.00 emerged, and the scree plot supported that there was a drop in variance explained after 4 factors. Three items loaded weakly on the intended dimension and had strong cross-loadings, so were omitted (see Table 1). In general, the factor structure supported the ideas of SERF, loss of control, instrumental and relational outcomes as distinct.

The final six items for SERF had an alpha coefficient of .80 and the inclusion of one omitted item did not increase this coefficient. Thus, these six items were used to compute a scale of fairness of display rules. The two relational outcomes $($ alpha $=.71)$ and loss of control (alpha $=.73)$ had reasonable alpha coefficients. The three instrumental outcomes had a low alpha (.58) that would be increased to .65 by omitting the item "pleases my supervisor". Thus, each of the three perceptions of display rules composites were formed with two items.

The newly formed composites of SERF, and perceptions of instrumental outcomes, relational outcomes, and control, were correlated with all other variables as an initial test of the propositions. See Table 2 for bivariate correlations.

\section{INSERT TABLE 2 ABOUT HERE}

As proposed by Proposition 1-4, SERF was significantly correlated with turnover intentions, perceptions of control, instrumental outcomes and relational outcomes in the predicted directions. The more employees believed that display rules were fair, the less likely they were to intend to quit the jobs. Furthermore, perceptions that "service with a smile" entailed a loss of control were negatively correlated with fairness perceptions. Lastly, the more employees perceived that display rules were instrumental for job rewards and gave an opportunity to express oneself with customers, display rules were evaluated as fairer.

It is interesting to note that only positive affectivity was associated with SERF and neither negative affectivity nor expressive confidence were significantly related, supporting that SERF is a distinct type of individual difference. However, affective disposition correlated with the perceptions of outcomes from display rules. Perceived instrumental outcomes were significantly related to positive affectivity and marginally associated with negative affectivity. Both positive and negative affectivity were significantly related with perceived relational outcomes.

To examine the group comparisons in Proposition 4 through 8 , a series of $t$-tests were computed. The mean differences in perceptions of SERF are shown in Figure 1 (see Figure 1). Men and women did not significantly differ in their perceptions of display rules or SERF. Thus, no support was found for Propositions 5a and 5b. Support was found for racial group differences: the Caucasian group rated display rules as less controlling $(M=1.76)$ than minority employees $(M=2.39, p<.01)$ in support of Proposition 6a, and as more fair overall than the minority group members (see Figure 1) in support of Proposition 6b. The other perceptions of display rule outcomes were not significantly different for these two groups. 


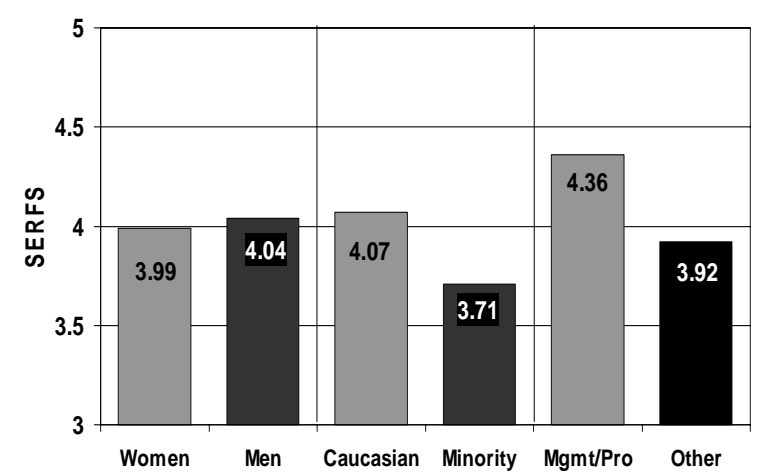

Figure 1: Group differences in Service Emotion Rules Fairness Scale (SERFS)

Finally, Proposition 7 was supported in that those who held managerial/professional jobs reported higher SERF values than those in other job categories (see Figure 1). When examined by individual categories, manager/professionals had significantly higher SERF levels with every other job category. So, men and women were similarly likely to respond to display rules. However, those with higher social status (majority group) or job status (managers/professionals) were more likely to rate display rules as fair than compared to those with lower status.

As a follow-up analysis, paired t-tests were performed to determine if the perceptions of display rules were reported at significantly different levels. Instrumental rewards were most likely $(M=4.37, S D=.59)$, followed by relational $(M=3.86, S D=.84)$, and least likely was feeling controlled $(M=1.87, S D=.93)$. All comparisons were significant $(p<.001)$. This is similar to Adelmann's (1995) finding that there was little support that people were 'against' display rules or that they were viewed as controlling, as proposed by Hochschild (1983).

\section{Predicting SERF and Job Strain}

To examine the unique prediction of SERF hierarchical regressions were performed. The group membership, affective personality and perceptions of display rules policy and outcomes explained $34 \%$ of the variance in $\mathrm{SERF}^{2}$. Having a managerial or professional job, beyond all other variables, made one significantly more likely to believe that display rules for service workers were

\footnotetext{
${ }^{2}$ Regression tables can be obtained from the first author by request.
}

fair (beta $=.23, p<.05$ ), while disposition did not significantly add to the variance explained in SERFs. The perceptions of display rules contributed $20 \%$ to the variance explained: the perception of relational outcomes (beta $=.35, p$ $<.01$ ) and loss of control (beta $=-.24, p<.05$ ) were significant unique predictors. The fact that perception of instrumental outcomes was not significant supports Proposition 4; relational outcomes will have more impact on display rule fairness than instrumental outcomes. Overall, fairness of display rules seems to be determined by the extent that something is gained or lost personally from service with a smile. Managers and professionals have been found to gain an increase in salary when they are expected to do emotion work (Glomb et al., in press), whereas front-line service workers do not see such an increase. Instead, employees find display rules fair to the extent that they get positive interactions with others and do not feel that those interactions are controlled by the organization.

Together, group membership, affective personality, perceptions of policy and outcomes, and SERF explained $33 \%$ of the variance in turnover intentions. Managerial/professional status was a significant predictor (beta $=-.21, p$ $<.05)$ that reduced to marginal significance when SERF was entered. Negative affectivity and expressive confidence correlated with turnover intentions as well. SERF explained 3\% unique variance in this behavioral intention $(p=$ .08 ), providing some support that SERF adds to the prediction of job strain and the idea that when policies are viewed as fair, withdrawal is less likely (Masterson et al., 2000).

The above study was conducted to provide evidence for the construct of fairness of display rules. Fairness of display rules seems to be an individual difference that is unique from positive and negative affectivity and expressive confidence, and is explained by perceptions of gains or losses from display rules. Importantly, we demonstrated a relationship between SERF and job strain. Those persons who found display rules less fair were more likely to intend to quit their jobs, and this was not accounted for by affective personality or group membership. One main limitation of the demonstrated association with intentions to quit is that this is not a direct 
measure of job strain. Furthermore, all the measures were self-reported at one point in time. Another issue is that these respondents had already self-selected into jobs that involved customer contact, and thus may handle the job requirements better. An experimental study was designed to correct for these issues and further examine the relationship of SERF with job strain.

\section{STUDY 2: \\ SERF AND JOB STRAIN EXPERIMENT}

Study 1 provided evidence for the SERF construct. In Study 2, an experimental design was used to examine the effect of SERF on postmeasures of strain after engaging in service encounters.

\section{Method}

\section{Participants and Procedures}

Fifty-one undergraduate students (42\% males, $79 \%$ white, mean age 20.96 years old) from a large university in the Northeast participated in a simulated call center study in which they served as a customer-service representative for a fictional office supply store. First, participants completed a short survey assessing their positive affectivity, negative affectivity and perceptions regarding the fairness of display rules. Participants were then given a half-hour training session where instructions for completing customer order forms and the expectations for efficient and accurate work was communicated. In addition to these task-related instructions, participants were randomly assigned to one of three conditions. In one condition, no explicit display rules were given $(\mathrm{N}=17)$, while the remaining participants $(\mathrm{N}=34)$ were told that following display rules (hide negative or show positive) was part of their role.

The participants then moved to another room where they handled three incoming calls from customers who, in actuality, were experiment confederates. To increase the realism of the simulation, task and emotional requirements were varied - for example, the second caller behaved in a negative manner, and the third asked for a product by name but did not have the identifying code or page number. The participants completed scales about their strain and the perceived fairness of the display expectations in the simulation.

\section{Measures}

The same original SERF items were included, and again the one item regarding the reprimanding employees needed to be eliminated in order to increase the reliability of the scale. Thus, the same six items as in Study 1 were formed into a composite (alpha $=.71$ ). The same positive and negative affectivity items were used (PA alpha $=.79$; NA alpha $=.87$ ). The five-item Job-related Exhaustion scale by Wharton (1993) was revised to refer to the extent of fatigue felt at the end of the simulation (alpha $=.92)$. Lastly, the participants were asked to rate the fairness of the requirements of the job they had completed. These items were: "The requirements of this job were fair," The requirements were consistent with my expectations for this type of work", and "the job expectations were unfairly high" (alpha $=.88$ ). This was to examine if the general SERF scale, completed prior to the simulation, would predict their fairness of the specific work requirements they were given.

\section{Results \& Discussion}

In order to ascertain whether SERF predicted job strain (Proposition 1) two approaches were taken. First, SERF should predict job strain when display rules are required, because that is when the person should experience role conflict. SERF should be less likely to predict strain if the individual does not, him- or herself, have to follow display rules. Thus, we first dichotomized SERF (+/- 1 SD) and then conducted a 2 (display rules or not) $\mathrm{x} 2$ (SERF high or low) ANOVA on the outcome. As the next step, we performed a hierarchical regression to determine whether SERF predicted strain beyond affective personality for the participants in the display rules condition.

\section{Hypothesis Testing}

The 2 x 2 ANOVA predicting job strain revealed a marginally significant interaction for assigned display rules and fairness of display rules for service workers $[\mathrm{F}(1,12)=4.12, p=$ $.065]$. The means were graphed (see Figure 2). 
These results support that fairness of display rules was more likely to predict job strain when display rules were required than when they were not. When positive displays were a requirement of the job, those who had reported that display rules were generally unfair were more exhausted (greater role conflict) in comparison to those who believed display rules were fairer (less role conflict). When positive displays were not a requirement, the SERF did not predict job strain; fairness of an abstract policy makes little difference to an employee's strain. This is supportive of the theoretical ideas behind SERF and a sense of role conflict between beliefs about emotional control and job requirements.

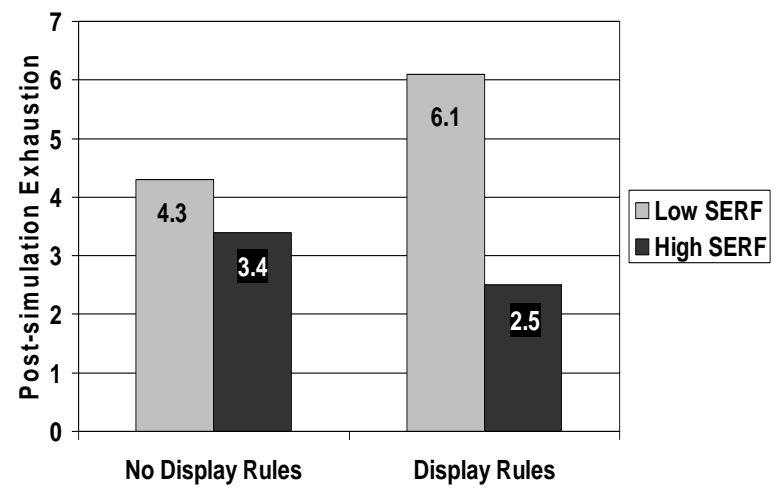

Figure 2: The interactive effect of display rules and service emotion rule fairness (SERF) on postsimulation exhaustion.

To examine further the role of SERF on job strain, post-simulation exhaustion was regressed onto SERF ratings, gender, and positive and negative affectivity for those participants in the display rule condition $(\mathrm{N}=34)$. For those persons who must work under display rules, the extent of their SERF beliefs should predict their job strain while controlling for the situational and individual characteristics. SERF strongly predicted exhaustion (beta $=-.60, p<.01, \Delta R^{2}=$ $.43)$. As evidence for convergent validity, we regressed the post-simulation fairness items on the pre-simulation SERF and the other predictors. SERF was the significant predictor (beta $=.50, p$ $<.01, \Delta R^{2}=.21$ ), demonstrating that the general perception of fairness of display rules for service workers was related to fairness of expectations in a job where display rules were required.
The results support the psychometrics of the six-item SERF scale with a different sample, and demonstrate that the level of SERF predicted employee strain for those who work under explicit display rules better than those who do not, as would be expected. Furthermore, SERF was a strong predictor of the extent of exhaustion after performing a service job, beyond gender and affective disposition.

\section{CONCLUSIONS AND FUTURE DIRECTIONS}

The purpose of this chapter was to propose a new type of individual difference to understand the job strain experienced by the many employees who work within the service industry. This individual difference was a cognitive belief, rather than an affective disposition or situational event, as is normally examined, and represents the extent to which display rules regulating service employee's emotions at work are perceived as fair. We proposed that SERF matters in predicting job strain, and perceptions about the policy and its outcomes and group membership would contribute to the level of SERF. Two studies were presented that provide initial evidence for the validity and utility of SERF in future research on job strain in service.

\section{Are Display Rules Generally Unfair?}

Hochschild (1983) proposed that organizational rules that regulate emotional expressions would be viewed as inherently unpleasant. Such requirements remove personal control over a personal aspect of identity emotional expression - and may be viewed as extraneous and onerous when expected in addition to task performance requirements. The fact that service work is often associated with the low pay, low status and rude customers may add insult to injury and make display rules stressful. So, do people believe that display rules that control service workers' emotions are fair or not? Overall, the mean levels of the scale items $(\mathrm{SERF}=$ service emotion rules fairness) in Study 1 suggested that most of the participants believed that these rules were fair $(\mathrm{M}=4.01$ on a five point scale). However, all of these respondents were already in jobs that required 
customer contact. In Study 2, the participants were students who were assigned to working conditions. In that group, the average level of SERF was closer to the midpoint $(\mathrm{M}=4.57$ on a seven point scale). This suggests that there is self-selection into jobs based on this fairness belief, such that the fairness perception is skewed and restricted for those in service jobs. It may also be that individuals convince themselves that the policy is fair, via cognitive dissonance processes, once they hold jobs with display rules.

\section{Does SERF matter? Fairness of Display Rules and Job Strain}

Previous research suggests that stress is often induced by external conditions (e.g., job demands such as display rules) which in turn, challenge an individual's status and self-esteem (Hobfoll, 1989). Display rules function as a type of work-related demand and in general may serve as a source of role stress and contribute to burnout and turnover (see Lee \& Ashforth, 1996). Furthermore, display rules are a special type of job requirement - they control (inspire?) employee's emotions, generally thought to be an internal and personal aspect of the self. People are likely to vary in the degree to which they believe such requirements are fair or appropriate. We argued that when employees view display rules as unfair, those display rules are more likely to act as a stressor, inducing intentions to quit and exhaustion in the employee. As stated earlier, this is an internal form of role conflict, where the employee's beliefs and job requirements are incompatible.Using two different populations and methods, we identified that SERF is predictive of signs of strain beyond affective personality and when environmental stressors are controlled.

Turnover intentions are a sign of job strain and dissatisfaction, and turnover is a critical issue in the service sector. Employees with customer contact in a wide range of positions who felt that display rules were less fair were more likely to intend to quit their jobs. The bivariate correlation supported this relationship. In addition, SERF explained a unique amount of the variance in turnover intentions; those who felt that emotion display rules were unfair requirements were more likely to desire to quit their customer contact jobs, and this effect existed beyond affective disposition and group membership.

The experimental data also supported that more strain was felt by those who worked under display rules but felt they were unfair requirements. In this case, participants reported their beliefs concerning SERF prior to engaging in the experimental simulation. After performing the tasks and interacting with customers who varied in their interpersonal demeanor, participants recorded their felt exhaustion. SERF beliefs were irrelevant for those who did not receive display rules, thus, SERF does not simply represent a predisposition to job strain. Participants who experienced role conflict - they were assigned to a display rule condition but had reported that they thought display rules were unfair - were more exhausted at the end of the study than those who thought display rules were fair. Moreover, SERF explained exhaustion beyond affectivity and gender among those in the display rule conditions after controlling for situational stressors and environmental factors. This provides evidence for SERF as an explanatory factor for the strain of people work.

What Contributes to the Fairness of Display Rules?

As expected based on the justice literature, when benefits were associated with display rules the policies were seen in a more positive light. Those employees who believed that positive displays served as a means of selfexpression and as an opportunity to form relational bonds were less likely to think that display rules were unfair. On the other hand, when display rules were seen as resulting in a loss of control and identity, these rules were reported as being unfair. It should be noted that while instrumental beliefs about smiling at customers were related to fairness of display rules, they did not predict SERF beyond the other (e.g., relational) beliefs. This is consistent with organizational justice theories suggesting that relational aspects of policies drive fairness perceptions beyond the distributions (Tyler, 1994).

In terms of individual differences, the results generally supported that SERF represented a unique individual difference that could not be fully explained by affectivity or 
confidence in expressive abilities. Positive affectivity (PA) had a significant relationship with SERF, but did not predict fairness beyond more proximal beliefs regarding the outcomes of following display rules. Negative affectivity (NA) and expressive confidence were weakly related to SERF. However, these affective characteristics did relate to beliefs about the outcomes of display rules. Those higher in PA were more likely to believe that instrumental and relational outcomes would follow positive displays to customers, and less likely to feel a loss of control from following display rules. In other words, those who are predisposed to feel positively recognize that they are more likely to reap the benefits of display rules. Those high in negative affectivity (NA) were less likely to believe that positive displays resulted in relational or instrumental outcomes and were more likely to endorse the view that display rules are a control mechanism and lead to alienations from real feelings. Since individuals high in NA would likely need to engage in more suppression and faking (i.e., surface acting), it is understandable that they would be less likely to expect positive outcomes. The fact that PA and NA were not strongly related to SERF demonstrates its distinctiveness from these affective personality factors that have typically been examined in the literature on display rules.

There were also some significant differences between groups in the perceived fairness of service display rules. Caucasian respondents were more likely to rate display rules as fair than minority respondents. Interestingly, these two groups did not vary in the extent that they worked under display rules. However, they did vary in their views regarding whether display rules were associated with a loss of personal control. Minority group members were more likely than majority group members to report that smiling at customers made them feel used. We proposed this reaction would be due to a higher likelihood of having to deal with negative / racist events in the work environment and a need to do more impression management to manage stereotypes others hold (Clark et al., 1999). The role of race in determining reactions to display rules within the context of a customer-employee service interaction should be examined further.
Furthermore, people who held managerial or professional positions were significantly more likely to report that such display requirements were fair. It is interesting to note that these employees also reported having to follow display rules at levels similar to service and caring workers (as found by Brotheridge \& Grandey, 2002). Thus, the observed difference in fairness is not because managers do not have to worry about such requirements. Instead, the difference may be because higher status jobs have more latitude of expression within display rules, and they are more likely to be compensated for these expressive requirements (Glomb et al., in press).

\section{Future Research}

Future research should examine how people in other culturally distinct countries perceive emotion display rules, specifically display rules in service encounters. Furthermore, combinations of the factors outlined in this paper should be examined. For example, how might someone who is a manager and a minority perceive display rules as compared to a Caucasian lower-status employee? Previous work suggests that low status females would be viewed more negatively for breaking display rules than someone who is male or working in a higher status occupation (Berger, Fisek, \& Norman, 1989). The role of emotional expressions in maintaining power differentials would be an interesting avenue to explore.

In terms of outcomes, future research should test if those who have lower SERF experience have higher physiological arousal when given display rules. Furthermore, comparing the extent of arousal when there is a mismatch between SERF beliefs and the job expectations, to when there is a mismatch between affective disposition and job expectations, would be informative about SERFs predictive validity. Is the extent of role conflict and internal dissonance more stressful when beliefs about emotional control (the willingness to follow display rules) are in contrast with the rules, or when personal affectivity (the ability to follow display rules) is in contrast with the rules? The comparative strength of fairness beliefs over affective disposition was shown 
here. An interaction between the two may also be possible such that positive affectivity relates to less strain when fairness is high but not when fairness is low (ability x motivation interaction).

\section{Practical Implications}

Practically speaking, it may be worthwhile to enhance employees' SERF if they are holding jobs where certain displays are required. Overall, the finding that perceptions regarding the fairness of display rules are independent from individual difference constructs such as affectivity and expressivity suggests that organizations may be able to adopt practices that would serve to improve how their employees view and respond to display rules. The grocery store case did not allow for such personal control or voice, and this unchecked injustice resulted in receiving a lawsuit. Using SERF as part of selection or training may serve as a realistic job preview tool (see Wanous, 1980) and facilitate dialogue about display rules. This may help employees self-select into positions that match their beliefs about emotional control (Schneider, 1987). Managers may also improve SERF by following Leventhal's (1980) procedural justice criteria. For example, employees should be provided with an opportunity to participate in the creation of display rule policies as well as challenge decisions made on the basis of them. Drawing attention to the fairness of display rules may also be beneficial to the extent that it promotes a justice climate. Existing research suggests that when aggregated, perceptions of fairness are associated with improvements in employee performance, decreases in absenteeism and higher levels of customer service (e.g., Colquitt, Noe \& Jackson, 2002; Simons \& Roberson, 2003). Thus, ensuring that employees perceive display rules as fair may have a "trickledown" or spillover effect on customer satisfaction and the bottom line (Masterson, 2001; Bowen, Gilliland \& Folger, 1999).

Organizations may also be able to enhance SERF in service employees and thereby indirectly decrease conflict and strain. During training and socialization processes, managers should strive to make the link between behavior and rewards explicit (Vroom, 1964) and to explain or justify the rationale behind display policies (Greenberg, 1990, 1994). This may mean discussing research that demonstrates the linkages between displays and rewards such as tips, customer satisfaction, and customer repatronage intentions (Pugh, 2001; Tidd \& Lockard, 1978; Tsai, 2001; Tsai \& Huang, 2002). In addition to the importance of highlighting instrumental outcomes, this paper also shows the importance service workers attach to relational considerations. Brotheridge and Lee (2002) note that employee attempts to comply with display rules (via surface acting) could result in resource drain which may be counteracted by establishing meaningful relationships with others. Indeed, the authors maintain that a "lack of rewarding relations affects personal accomplishment through authenticity" which in turn, "fuels the vicious cycle of burnout" (Brotheridge \& Lee, 2002, p. 65). Given the characteristics of front-line service work described here (e.g., low status, rude customers) it is rare that service employees will be able to establish meaningful relationships with the people they assist. To counteract poor customer-employee relations, it is important that employees feel that in the event of a problem, the organization will support them and their behavior (Eisenberger, Huntington, Hutchison, \& Sowa, 1986).

As one of the fastest growing jobs of the U.S. economy, service employees' strain and turnover is a critical problem. We propose that the perception of fairness of display rules may help predict who will be a poor fit for service work and explain levels of job strain. Nevertheless, the data presented here are preliminary. There are many individual difference variables that predict stress. The value SERF is that it is specific to this population, but its unique contribution still needs further examination. However, in the minds of these authors, when understanding stress of display rules, we think fairness has something to do with it.

\section{References}

Abraham, R. (1999). Negative affectivity: Moderator or confound in emotional dissonanceoutcome relationships? The Journal of Psychology, 133(1), 61-72. 
Adelmann, P. K. (1995). Emotional labor as a potential source of job stress. In S. L. Sauter \& L. R. Murphy (Eds.), Organizational risk factors for job stress (pp. 371-381). Washington, DC: American Psychological Association.

Allan, S., \& Gilbert, P. (2002). Anger and anger expression in relation to perceptions of social rank, entrapment, and depressive symptoms. Personality and Individual Differences, 32, 551-565.

Arvey, R. D., Renz, G. L., \& Watson, W. W. (1998). Emotionality and job performance: Implications for personnel selection. Research in Personnel and Human Resources Management, 16, 103-147.

Ashforth, B. E., \& Humphrey, R. H. (1993). Emotional labor in service roles: The influence of identity. Academy of Management Review, 18(1), 88-115.

Ashforth, B. E., \& Tomiuk, M. A. (2000). Emotional labor and authenticity: Views from service agents. In S. Fineman (Ed.), Emotion in Organizations (2nd ed., pp. 184-203). Thousand Oaks, CA: Sage.

Berger, J., Fisek, M. H., \& Norman, R. Z. (1989). The evolution of status expectations. A theoretical extension. In J. Berger \& J. M. Zelditch \& B. Anderson (Eds.), Sociological theories in progress. London: Sage.

Best, R. G., Downey, R. G., \& Jones, R. G. (1997, April). Incumbent perceptions of emotional work requirements. Paper presented at the 12th annual meeting of the Society for Industrial and Organizational Psychology, St.Louis, Missouri.

Bowen, D. E., Gilliland, S. W., \& Folger, R. (1999). HRM and service fairness: How being fair with employees spills over to customers. Organizational Dynamics, 27, 7-23.

Brotheridge, C., \& Grandey, A. (2002). Emotional labor and burnout: Comparing two perspectives of "people work". Journal of Vocational Behavior, 60, 17-39.

Brotheridge, C.M., \& Lee, R.T. (2002). Testing a conservation of resources model of the dynamics of emotional labor. Journal of Occupational Health Psychology, 7, 57-67.

Bugental, D. E., Love, L. R., \& Gianetto, R. M. (1971). Perfidious feminine faces. Journal of Personality and Social Psychology, 17, 314318.

Bulan, H. F., Erickson, R., \& Wharton, A. (1997). Doing for others on the job: The affective requirements of service work, gender, and emotional well-being. Social Problems, 44(2), 235-256.
Cabanatuan, M. (1998, September 3). Let's-be-pals policy turns off some Safeway shoppers. San Francisco Chronicle, pp. A19.

Clark, R., Anderson, N. B., Clark, V. R., \& Williams, D. R. (1999). Racism as a stressor for African Americans: A biopsychosocial model. American Psychologist, 54(10), 805816.

Colquitt, J. A., Conlon, D.E., Wesson, M.J., Porter, C., Ng, K.Y. (2001). Justice at the Millennium: A meta-analytic review of 25 years of organizational justice research. Journal of Applied Psychology, 86(3), 425445.

Colquitt, J.A., Noe, R.A., \& Jackson, C.L. (2002). Justice in teams: Antecedents and consequences of procedural justice climate. Personnel Psychology, 55, 83-109.

Côté, S., \& Morgan, L. (2002). A longitudinal analysis of the association between emotion regulation, job satisfaction, and intentions to quit. Journal of Organizational Behavior, 23, 947-962.

Cropanzano, R., \& Ambrose, M. L. (2001). Procedural and distributive justice are more similar than you think: A monistic perspective and a research agenda. In J. Greenberg \& R. Cropanzano (Eds.), Advances in organizational justice (pp. 119151). Stanford, CA: Stanford University Press.

Cropanzano, R., Byrne, Z. S., Bobocel, D. R., \& Rupp, D. E. (2001). Moral virtues, fairness heuristics, social entities, and other denizens of organizational justice. Journal of Vocational Behavior, 58, 164-209.

Cropanzano, R., James, K., \& Konovsky, M. A. (1993). Dispositional affectivity as a predictor of work attitudes and job performance. Journal of Organizational Behavior, 14, 595-600.

Curtis, K. (1998). Smiley face out of place at Safeway, workers say. The Oregonian, p. 3.

Diefendorff, J. M., Croyle, M., \& Gosserand, R. (in press). The dimensionality and antecedents of emotional labor strategies. Journal of Vocational Behavior.

Diefendorff, J.M., \& Gosserand, R.H. (2003). Understanding the emotional labor process: A control theory perspective. Journal of Organizational Behavior, 24, 945-959.

Diefendorff, J. M., \& Richard, E. (2003). Antecedents and consequences of emotional display rule perceptions. Journal of Applied Psychology, 88(2), 284-294. 
Eisenberger, R., Huntington, R., Hutchison, R., \& Sowa, D. (1986). Perceived organizational support. Journal of Applied Psychology, 71, 500-507.

Ekman, P., \& Friesen, W. V. (1975). Unmasking the face: A guide to recognizing emotions from facial clues. Englewood Cliffs, NJ: PrenticeHall.

Emerson, R. E. (1962). Power dependence relations. American Sociological Review, 27, 31-41.

Fischer, A. (1993). Sex differences in emotionality: Fact or stereotype? Feminism \& Psychology, 3, 303-318.

Glomb, T., Kammeyer-Mueller, J., \& Rotundo, M. (in press). Emotional labor and compensating wage differentials. Journal of Applied Psychology.

Goffman, E. (1967). Interaction ritual: Essays on face-to-face behavior. Garden City, NY: Anchor Books.

Graham, J. W., Gentry, K. W., \& Green, J. (1981). The self-presentational nature of emotional expression: Some evidence. Personality and Social Psychology Bulletin, 7(467-474).

Grandey, A., \& Brauburger, A. (2002). The Emotion regulation behind the customer service smile. In R. Lord \& R. Klimoski \& R. Kanfer. (Eds.), Emotions in the workplace: Understanding the structure and role of emotions in organizational behavior. (pp. 260-294). San Francisco, CA: Jossey-Bass.

Grandey, A., Dickter, D., \& Sin, H.-P. (2004). The customer is not always right: Customer verbal aggression toward service employees. Journal of Organizational Behavior, 25(3), 397-418.

Grandey, A., Fisk, G., \& Steiner, D. (2004). Investigating French and American Service Workers' Reactions to "Service with a Smile". Paper presented at the Society of Industrial and Organizational Psychologists, Chicago, IL.

Grandey, A., Tam, A., \& Brauburger, A. (2002). Affective states and traits of young workers: A diary study. Motivation and Emotion, 26(1), 31-55.

Greenberg, J. (1987). A taxonomy of organizational justice theories. Academy of Management Review, 12, 9-22.

Greenberg, J. (1990). Employee theft as a reaction to underpayment inequity: The hidden cost of pay cuts. Journal of Applied Psychology, 75(5), 561-568.

Greenberg, J. (1994). Using socially fair treatment to promote acceptance of a work site smoking ban. Journal of Applied Psychology, 79(2), 288-297.

Gross, J., \& John, O.P. (1998). Mapping the domain of expressivity: Multimethod evidence for a hierarchical model. Journal of Personality and Social Psychology, 74(1), 170-191.

Gross, J., \& John, O. (2003). Individual differences in two emotion regulation processes: Implications for affect, relationships, and well-being. Journal of Personality and Social Psychology, 85(2), 348-362.

Gross, J., \& Levenson, R. (1993). Emotional suppression: Physiology, self-report, and expressive behavior. Journal of Personality and Social Psychology, 64, 970-986.

Gross, J., \& Levenson, R. (1997). Hiding feelings: The acute effects of inhibiting negative and positive emotions. Journal of Abnormal Psychology, 106(1), 95-103.

Haynes, S., Levine, S. P., Scotch, N., Feinleib, M., \& Kannel, W. B. (1978). The relationship of psychosocial risk factors to coronary heart disease in the Framingham Study. American Journal of Epidemiology, 107, 362-383.

Hecht, M. A., \& LaFrance, M. (1998). License or obligation to smile: The effects of power and gender on amount and type of smiling. Personality and Social Psychology Bulletin, 24, 1332-1342.

Henley, N. M. (1977). Body politics: Power, sex, and nonverbal communication. Berkeley Review of Sociology, 18, 1-26.

Hobfoll, S.E. (1989). Conservation of resources: A new attempt at conceptualizing stress. American Psychologist, 44, 513-524.

Hochschild, A. R. (1979). Emotion work, feeling rules, and social structure. American Journal of Sociology, 85(3), 551-575.

Hochschild, A. R. (1983). The managed heart: Commercialization of human feeling. Berkeley, CA: University of California Press.

Karasek, R. A. (1979). Job demands, job decision latitude, and mental strain: Implications for job redesign. Administrative Science Quarterly, 24, 285-308.

LaFrance, M., \& Hecht, M. A. (1999). Option or obligation to smile: The effects of power and gender on facial expression. In $\mathrm{P}$. Philippot \& R. S. Feldman \& E. J. Coats (Eds.), The social context of nonverbal behavior (pp. 45-70). New York: Cambridge University Press.

Lee, R.T., \& Ashforth, B.E. (1996). A meta-analytic examination of the correlates of the three 
dimensions of job burnout. Journal of Applied Psychology, 81, 123-133.

Leidner, R. (1996). Rethinking questions of control: Lessons from McDonald's. In C. L. Macdonald \& C. Sirianni (Eds.), Working in the service society (pp. 29-49). Philadelphia, PA: Temple University Press.

Lerner, G. (1985). The dance of anger. New York: Harper \& Row.

Leventhal, G. S. (1976). Fairness in social relationships. In J. W. Thibault \& J. T. Spence \& R. C. Carson (Eds.), Contemporary topics in social psychology (pp. 211-240). Morristown, NJ: General Learning Press.

Leventhal, G.S. (1980). What should be done with equity theory? In K.J. Gergen, M.S. Greenberg \& R.H. Willis (Eds.), Social exchange: Advances in theory and research (pp. 27-55). New York: Plenum.

Lind, E. A. (1995). Justice and authority in organizations. In R. Cropanzano \& M. K. Kacmar (Eds.), Organizational politics, justice and support: Managing the social climate of the workplace. Westport, CT: Quorum Books.

Lind, E. A., \& Tyler, T. R. (1988). The social psychology of procedural justice. New York.: Plenum.

Martin, J., Knopoff, K, Beckman, C. (1998). An alternative to bureaucratic impersonality and emotional labor: Bounded emotionality at The Body Shop. Administrative Science Quarterly, 43, 429-469.

Maslach, C. (1978). The client role in staff burn-out. Journal of Social Issues, 34(4), 111-124.

Maslach, C., \& Pines, A. (1977). The burn-out syndrome in the day care setting. Child Care Quarterly, 6, 100-113.

Maslach, C., \& Jackson, S. E. (1984). Patterns of burnout among a national sample of public contact workers. Journal of Health and Human Resources Administration, 7, 189212.

Masterson, S. S. (2001). A trickle-down model of organizational justice: Relating employee customers' perceptions of and reactions to fairness. Journal of Applied Psychology, 86(4), 594-604.

Masterson, S. S., Lewis, K., Goldman, B. M., \& Taylor, M. S. (2000). Integrating justice and social exchange: The differing effects of fair procedures and treatment on work relationships. Academy of Management Journal, 43, 738-748.

Matsumoto, D. (1993). Ethnic differences in affect intensity, emotion judgments, display rule attitudes, and self-reported emotional expression in an American sample. Motivation and Emotion, 17(3), 107-123.

Mikula, G., Scherer, K. R., \& Athenstaedt, U. (1998). The role of injustice in the elicitation of differential emotional reactions. Personality and Social Psychology Bulletin, 24, 769783.

Morris, J. A., \& Feldman, D. C. (1996). The dimensions, antecedents, and consequences of emotional labor. Academy of Management Review, 21(4), 986-1010.

Morris, J. A., \& Feldman, D. C. (1997). Managing emotions in the workplace. Journal of Managerial Issues, 9(3), 257-274.

Mossholder, K. W., Bennett, N., Kemery, E. R., \& Wesolowski, M. A. (1998). Relationships between bases of power and work reactions: The mediational role of procedural justice. Journal of Management, 24(533-552).

Offermann, L. R., \& Gowing, M. K. (1990). Organizations of the future: Changes and challenges. American Psychologist, 45, 95108.

Pugh, S. D. (2001). Service with a smile: Emotional contagion in the service encounter. Academy of Management Journal, 44(5), 1018-1027.

Pugliesi, K. (1999). The consequences of emotional labor: Effects on work stress, job satisfaction, and well-being. Motivation and Emotion, 23(2), 125-154.

Rafaeli, A., \& Sutton, R. I. (1987). Expression of emotion as part of the work role. Academy of Management Review, 12(1), 23-37.

Rosenfeld, P., Giacalone, R. A., \& Riordan, C. (1994). Impression management theory and diversity: Lessons for organizational behavior. American Behavioral Scientist, 37(601-604).

Schaubroeck, J., \& Jones, J. R. (2000). Antecedents of workplace emotional labor dimensions and moderators of their effects on physical symptoms. Journal of Organizational Behavior, 21, 163-183.

Schneider, B. (1987). The people make the place. Personnel Psychology, 40, 437-453.

Shields, S. (1987). Women, men, and the dilemma of emotion. In P. Shaver \& C. Hendrick (Eds.), Sex and gender (pp. 229-250). Newbury Park, CA: Sage.

Sideman, L., \& Grandey, A. (2003, August). Emotion regulation in a simulated call center: A test of the ego depletion model. Paper presented at the Academy of Management, Seattle, WA. 
Simons, T., \& Roberson, Q. (2003). Why managers should care about fairness: The effects of aggregate justice perceptions on organizational outcomes. Journal of Applied Psychology, 88, 432-443.

Singh, J., Goolsby, J. R., \& Rhoades, G. K. (1994). Behavioral and psychological consequences of boundary spanning burnout for customer service representatives. Journal of Marketing Research, 16, 558-569.

Snyder, M. (1974). Self-monitoring of expressive behavior. Journal of Personality and Social Psychology, 30, 526-237.

Sparks, B. A., \& McColl-Kennedy, J. R. (2001). Justice strategy options for increased customer satisfaction in a services recovery setting. Journal of Business Research, 54, 209-218.

Spector, P. E. (1986). Perceived control by employes: A meta-analysis of studies concerning autonomy and participation at work. Human Relations, 11, 1005-1016.

Terkel, S. (1972). Working. New York: The New Press.

Tews, M. J., \& Glomb, T. (April, 2003). Emotional Labor and the Five-Factor Model of Personality. Paper presented at the Society for Industrial-Organizational Psychologists, Orlando, FL.

Tidd, K. L., \& Lockard, J. S. (1978). Monetary significance of the affiliative smile: A case for reciprocal altruism. Bulletin of the Psychonomic Society, 11, 344-346.

Tolich, M. B. (1993). Alienating and liberating emotions at work: Supermarket clerks' performance of customer service. Journal of Contemporary Ethnography, 22(3), 361-381.

Tsai, W.-C. (2001). Determinants and consequences of employee displayed positive emotions. Journal of Management, 27, 497-512.

Tsai, W.-C., \& Huang, Y.-M. (2002). Mechanisms linking employee affective delivery and customer behavioral intentions. Journal of Applied Psychology, 87(5), 1001-1008.

Tyler, T.R. (1994). Psychological models of the justice motive: Antecedents of distributive and procedural justice. Journal of Personality and Social Psychology, 67, 850863.

VanMaanen, J., \& Kunda, G. (1989). Real feelings: Emotional expression and organizational culture, Research in Organizational Behavior (Vol. 11, pp. 43-103). Greenwich, CT: JAI Press.

Vroom, V. (1964). Work and motivation. New York: Wiley.

Wanous, J.P. (1980). Organizational entry: Recruitment, selection and socialization of newcomers. Reading, MA: AddisonWesley.

Watson, D., Clark, L. A., \& Tellegen, A. (1988). Development and validation of brief measures of positive and negative affect: The PANAS scales. Journal of Personality and Social Psychology, 54(6), 1063-1070.

Weiss, H., Suckow, K., \& Cropanzano, R. (1999). Effects of justice conditions on discrete emotions. Journal of Applied Psychology, 84(5), 786-794.

Wharton, A. S. (1993). The affective consequences of service work: Managing emotions on the job. Work and Occupations, 20(2), 205-232.

Wharton, A. S., \& Erickson, R. J. (1995). The consequences of caring: Exploring the links between women's job and family emotion work. The Sociological Quarterly, 36(2), 273-296.

Wright, T.A., \& Cropanzano, R. (1998). Emotional exhaustion as a predictor of job performance and voluntary turnover. Journal of Applied Psychology, 83, 486-493.

Zohar, D. (1995). The justice perspective of job stress. Journal of Organizational Behavior, 16, 487-495. 
Table 1

Factor Structure of SERF Items and Perceived Outcomes from Positive Displays to Customers.

\begin{tabular}{|c|c|c|c|c|c|}
\hline $\begin{array}{l}\mathrm{M} \\
(\mathrm{SD})\end{array}$ & Items & SERF $^{1}$ & Instr. $^{2}$ & Relat. $^{2}$ & Cont. $^{2}$ \\
\hline & SERF & & & & \\
\hline $\begin{array}{l}4.33 \\
(.96)\end{array}$ & $\begin{array}{l}\text { It seems reasonable for service employees to be told } \\
\text { to "smile" as part of their job. }\end{array}$ & .69 & & & \\
\hline $\begin{array}{l}4.28 \\
(.74)\end{array}$ & $\begin{array}{l}\text { It is fair for any employee to be expected to hide } \\
\text { negative feelings from customers }\end{array}$ & .66 & & & \\
\hline 4.03 & Smiling at customers even when one is upset seems & .71 & & & \\
\hline$(.89)$ & like a fair request to make of employees. & & & & \\
\hline $\begin{array}{c}4.06 \\
(1.03)\end{array}$ & $\begin{array}{l}\text { It is fair to expect service employees to smile: that is } \\
\text { part of what they are paid to do. }\end{array}$ & .76 & & & \\
\hline $\begin{array}{c}3.44 \\
(1.15)\end{array}$ & $\begin{array}{l}\text { Reprimanding employees who show their negative } \\
\text { emotions to customers is fair treatment of employees. }\end{array}$ & .34 & & .57 & \\
\hline $\begin{array}{c}2.53 \\
(1.18)\end{array}$ & $\begin{array}{l}\text { Service employees shouldn't have to pretend they } \\
\text { aren't upset at a customer when they really are } \\
\text { (reversed). }\end{array}$ & .50 & & & \\
\hline $\begin{array}{c}2.05 \\
(1.07)\end{array}$ & $\begin{array}{l}\text { It seems unfair for service employees to have to smile } \\
\text { at customers in addition to everything else (reversed). }\end{array}$ & .57 & & & \\
\hline $\begin{array}{l}4.22 \\
(.96)\end{array}$ & $\begin{array}{l}\text { Perceived Outcomes from Positive Displays } \\
\text { It results in better sales, tips or commissions. }{ }^{1}\end{array}$ & & .79 & & \\
\hline $\begin{array}{l}4.62 \\
(.57)\end{array}$ & It makes the customers feel good. & & .64 & & \\
\hline $\begin{array}{l}4.31 \\
(.84)\end{array}$ & It pleases my supervisor. & & .61 & & \\
\hline $\begin{array}{l}4.13 \\
(.81)\end{array}$ & It accurately indicates my friendly personality. & & & .82 & \\
\hline $\begin{array}{c}3.57 \\
(1.08)\end{array}$ & It's a true sign of how I really like people. & & & .80 & \\
\hline $\begin{array}{l}1.80 \\
(.98)\end{array}$ & $\begin{array}{l}\text { It makes me feel that I am being used by my } \\
\text { employer. }\end{array}$ & & & & -.81 \\
\hline $\begin{array}{c}1.94 \\
(1.07)\end{array}$ & It makes me feel unsure about what I really feel. & & & & -.85 \\
\hline $\begin{array}{l}3.95 \\
(.91)\end{array}$ & It makes me feel happy. & & .51 & & .44 \\
\hline $\begin{array}{c}3.40 \\
(1.21) \\
\end{array}$ & It helps in getting raises or promotions. & & .46 & -.36 & .40 \\
\hline
\end{tabular}

Note. Instructions: ${ }^{1}$ For the items tapping SERF, participants were asked "To what extent do you agree with the following statements about service work (not necessarily your job, but service work in general)?" ${ }^{2}$ For the items tapping the perceived outcomes from positive displays, Instrumental, Relational, and Control, participants were asked "To what extent do you agree that being nice and smiling at customers during the work day have the following outcomes FOR YOU, generally speaking?" Items in italics were not used in the final composites due to cross-loadings or low reliability coefficients. 
Table 2

Bivariate Correlations of Study 1 Variables

\begin{tabular}{lccccccccc}
\hline & $M$ & $S D$ & 1 & 2 & 3 & 4 & 5 & 6 & 7 \\
\hline 1. SERF & 4.01 & .70 & & & & & & \\
2. Instrumental outcomes & 4.37 & .59 & .33 & & & & & \\
3. Relational outcomes & 3.86 & .85 & .42 & .25 & & & & \\
4. Loss of control & 1.87 & .93 & -.40 & -.23 & -.23 & & & \\
5. Positive Affectivity & 3.75 & .53 & .22 & .31 & .27 & -.35 & & & \\
6. Negative Affectivity & 1.59 & .52 & -.12 & -.19 & -.25 & .20 & -.36 & & \\
7. Expressive Confidence & 2.80 & .82 & .08 & .05 & .07 & .04 & .14 & -.12 & \\
8. Turnover intentions & 2.43 & 1.31 & -.22 & -.19 & -.03 & .13 & -.26 & .30 & .25
\end{tabular}

Note: Correlations greater than .19 are significant $(\mathrm{p}<.05)$. SERFS $=$ Service Emotion Rules Fairness. Responses are on a 5-point scale. 